\title{
Trends in the incidence of cryptorchidism and hypospadias of registry-based data in Korea: a comparison between industrialized areas of petrochemical estates and a non-industrialized area
}

\begin{abstract}
Sae Chul Kim ${ }^{1}$, Su Kyoung Kwon ${ }^{2}$ and Yeon Pyo Hong ${ }^{2}$
This study aimed to represent the recent trends in the nationwide incidence of cryptorchidism and hypospadias in Korea, and to determine whether there is evidence of spatial heterogeneity in the incidence. The incidence was calculated as the number of newly diagnosed patients (males) during the first 4 years after a live birth in a population, nationally and regionally (a non-industrialized area (Chuncheon) and petrochemical estates (Yeocheon and Ulsan)), between 2000 and 2005. The data (numerator) for new patients were acquired from the National Health Insurance Review Agency, and the data (denominator) for the resident registration population were from the National Statistical Office. Between 2000 and 2005, the national incidence of cryptorchidism and hypospadias had an increased tendency from 5.01 to 17.43 per 10000 persons and from 1.40 to 3.28 per 10000 persons, respectively. The incidence of cryptorchidism was significantly higher in Yeocheon (throughout the study period) and in Ulsan (2001, 2002, 2004 and 2005) than the national incidence, whereas the incidence in Chuncheon was significantly lower in 2001 and 2002. It was difficult to compare the rates of hypospadias yearly and regionally because of the small number of cases. In conclusion, the incidence of cryptorchidism has recently increased in Korea. The petrochemical estates, Yeocheon and Ulsan, had a significantly higher incidence of cyptorchidism than the national incidence, which suggests that further study is needed to obtain a more precise estimation of the trends in the incidence of the anomalies and to confirm the association between petrochemicals and the anomalies.
\end{abstract}

Asian Journal of Andrology (2011) 13, 715-718; doi:10.1038/aja.2010.53; published online 23 August 2010

Keywords: cryptorchidism; hypospadias; incidence; petrochemical estate

\section{INTRODUCTION}

Cryptorchism is the most common male genital anomaly identified at birth, affecting $2-4 \%$ of full-term male births. ${ }^{1}$ One-half of such testicles descend in the first month after birth, hence the prevalence of true cryptorchism at 1 year of age is $1-2 \% .^{2}$ Hypospadias is the most common congenital anomaly of the penis and has historically been identified in $0.3 \%$ of newborn boys. ${ }^{3}$ An overall increase in hypospadias in developed industrial countries of Europe and North America has been noted. ${ }^{4}$ Cryptorchidism can occur as an isolated disorder or may be associated with other congenital anomalies. Approximately $8-10 \%$ of boys with hypospadias have associated cryptorchidism. ${ }^{5}$

The etiology of cryptorchidism remains for the most parts unknown, and a large amount of research has focused on the possible genetic contribution to human cryptorchidism and on environmental factors acting as endocrine disruptors of testicular descent that might also contribute to the increased incidence of cryptorchidism in the recent decades. ${ }^{2}$ Cryptorchidism has been strongly and consistently related to the risk of testicular cancer, with more than a dozen studies reporting relative risks ranging from 2.1 to $17.6{ }^{6}$ The increase in the prevalence of hypospadias, cryptorchidsm, male infertility and testicular cancer observed in Western countries suggests a possible influence of environmental factors acting as endocrine disruptors. ${ }^{2,7}$ Cryptorchidism and hypospadias may be caused by antiandrogenic substances, such as phthalates, which are one of the main petrochemical products in the environment. ${ }^{8}$

There are no data on the nationwide incidence and/or prevalence of cryptorchidism and hypospadias in Korea. We represented the recent trends of the nationwide incidence of cryptorchidism and hypospadias compared with the industrialized areas of a petrochemical complex.

\section{MATERIALS AND METHODS}

The incidence of cryptorchidism and hypospadias was defined as the number of newly diagnosed patients (males) during the first 4 years after a live birth in a population. The number of newly diagnosed patients with cryptorchidism and hypospadias (the numerator) was acquired from the National Health Insurance Review Agency (NHIRA) of South Korea, nationally and regionally (non-industrialized area and industrialized areas with petrochemical complexes), 
Table 1 Population and frequency of $\mathrm{CO}$ and HS in males aged 0-4 years, nationally and regionally (Yeochon, Ulsan and Chuncheon), from 2000 to $2005^{a}$

\begin{tabular}{|c|c|c|c|c|c|c|c|c|c|c|c|c|}
\hline \multirow[b]{2}{*}{ Year } & \multicolumn{3}{|c|}{ National } & \multicolumn{3}{|c|}{ Yeochon } & \multicolumn{3}{|c|}{ Ulsan } & \multicolumn{3}{|c|}{ Chuncheon } \\
\hline & Population & $\mathrm{CO}$ & $H S$ & Population & $\mathrm{CO}$ & HS & Population & $\mathrm{CO}$ & $H S$ & Population & $\mathrm{CO}$ & $H S$ \\
\hline 2000 & 1689517 & 846 & 236 & 876 & 4 & 1 & 44370 & 27 & 1 & 8558 & 3 & 0 \\
\hline 2001 & 1621395 & 1821 & 420 & 844 & 5 & 0 & 42056 & 80 & 5 & 8221 & 1 & 0 \\
\hline 2002 & 1530531 & 1694 & 293 & 675 & 13 & 0 & 38993 & 70 & 15 & 7902 & 0 & 0 \\
\hline 2003 & 1450715 & 2265 & 434 & 632 & 13 & 1 & 36118 & 67 & 8 & 7471 & 9 & 2 \\
\hline 2004 & 1372979 & 2206 & 344 & 611 & 12 & 1 & 33627 & 78 & 4 & 6993 & 5 & 0 \\
\hline 2005 & 1263896 & 2156 & 406 & 707 & 14 & 1 & 30770 & 75 & 9 & 6380 & 7 & 0 \\
\hline
\end{tabular}

Abbreviations: CO, cryptorchidism; HS, hypospadias.

a Yeochon and UIsan are two industralized cities, while Chuncheon is a non-industrialized area.

from 2000 to 2005 . The data for the real population, which is the denominator, were acquired from the resident registration of the National Statistical Office of South Korea released by five age units every year. To avoid double counting, the resident registration number of new patients and addresses were compared. Table 1 shows the population and frequency of cryptorchidism and hypospadias, between the ages of 0 and 4 years, nationally and regionally. The incidence of cryptorchidism and hypospadias was measured on a scale of per 10000 people.

The survey was conducted nationwide and in three regions, which included two industrialized areas of petrochemical estates and one non-industrialized area. The non-industrialized area, Chuncheon City (CC), is a rural area in a central mountainous region of Korea, where a few administrative and educational centers are located. The two industrialized cities were Ulsan (UL) and Yeochon (YC). UL is an industrial center and is located on the southeast coast of the Korean peninsula; the industries of UL include automobile manufacturing, ship construction and petrochemical facilities. The other industrial center, YC, is located on the southwest coast and contains oil refineries and other petrochemical facilities. The atmospheric concentrations of $\mathrm{NO}_{2}$, total suspended particulates, $\mathrm{PM}_{10}$ and volatile organic compounds increased nationwide in South Korea between 2000 and 2005. ${ }^{9}$ The air in YC and UL area was highly polluted with $\mathrm{NO}_{2}$, $\mathrm{SO}_{2}$, total suspended particulates, $\mathrm{PM}_{10}, \mathrm{HCHO}$ and Volatile Organic Compounds (VOC) such as benzene, toluene, xylene, stylene, etc., including stylene and several hazardous aromatic and aliphatic species, whereas CC was one of the least polluted areas in South Korea.

The instruments used to manage health care security in South Korea comprise the Health Insurance System (HIS), which is funded by mandatory social insurance contributions and the Medical Aid Program (MAP) financed by the central government to provide medical service to the poor. The health care security system covers the whole population: $\sim 97 \%$ of the population is covered by HIS and the remaining $3 \%$ by MAP. When physicians request payment for a medical service to the Korean Health Insurance Corporation, they use International Classification of Disease codes for diagnosis and treatment. NHIRA then assesses all such requests for payment. We believe that this institutionalized standardized system probably increases the reliability of the data used.

The diagnosis of cryptorchidism and hypospadias was carried out by a four-rate assortment search in the International Classification of Disease 10. The diagnosis assortment code for cryptorchidismunilateral is Q531, cryptorchidism-bilateral is Q532 and cryptorchidism-unspecified is Q539. The diagnosis assortment code for hypospadias-balanic is Q540, hyposadias-penile is Q541, hypospadias-penoscrotal is Q542, hypospadias-perineal is Q543, other hypospadias is Q548 and hypospadias-unspecified is Q549. Table 2 shows frequency of the cryptorchidism and hypospadias according to four-character subcategories of the International Classification of Disease 10 in YC, UL and CC.

Statistical analysis was performed using Stata 10.0 (Stata Corp., College Station, TX, USA). The incidence rates between regions have been compared using exact Poisson 95\% confidence interval (CI).

\section{RESULTS}

\section{Cryptorchidism (cases per 10000 persons)}

The incidence rates of cryptorchidism and 95\% Poisson CI at ages of 0-4 years during 2000-2005 are recorded in Table 3. The national rate of the total newly diagnosed cases of cryptorchidism has significantly increased in 2001 and 2003, and continued to increase in 2004 and 2005. The rate in YC sharply increased in 2002 and further increased in 2003 and 2005. The rate in UL also sharply increased in 2001 and further increased in 2005. The rate of CC was lower than those of national, YC and UL throughout the study period. Throughout the

Table 2 Frequency of cryptorchidism and hypospadias using four-character subcategories of the International Classification of Disease 10 in Yeochon/UIsan/Chuncheon, respectively

\begin{tabular}{|c|c|c|c|c|c|c|c|c|c|c|c|}
\hline \multirow[b]{2}{*}{ Year } & \multicolumn{4}{|c|}{ Cryptorchidism } & \multicolumn{7}{|c|}{ Hypospadias $^{\mathrm{b}}$} \\
\hline & Q531 & Q532 & Q539 & Total & Q540 & Q541 & Q542 & Q543 & Q548 & Q549 & Total \\
\hline 2000 & 2/14/1 & $0 / 4 / 2$ & $2 / 9 / 0$ & $4 / 27 / 3$ & 0/0/0 & $1 / 1 / 0$ & 0/0/0 & 0/0/0 & 0/0/0 & 0/0/0 & $1 / 1 / 0$ \\
\hline 2001 & 2/36/1 & $1 / 10 / 0$ & $2 / 34 / 0$ & $5 / 80 / 1$ & $0 / 0 / 0$ & $0 / 1 / 0$ & $0 / 2 / 0$ & 0/0/0 & $0 / 1 / 0$ & $0 / 1 / 0$ & $0 / 5 / 0$ \\
\hline 2002 & $4 / 26 / 0$ & $1 / 6 / 0$ & $8 / 38 / 0$ & 13/70/0 & $0 / 1 / 0$ & $0 / 3 / 0$ & $0 / 4 / 0$ & 0/0/0 & 0/0/0 & 0/7/0 & $0 / 1 / 0$ \\
\hline 2003 & $2 / 23 / 4$ & $0 / 2 / 1$ & $11 / 42 / 4$ & $13 / 67 / 9$ & $0 / 2 / 1$ & $0 / 1 / 0$ & $1 / 0 / 0$ & 0/0/0 & 0/0/0 & $0 / 5 / 1$ & $1 / 8 / 2$ \\
\hline 2004 & $1 / 32 / 2$ & $1 / 13 / 0$ & $10 / 33 / 3$ & $12 / 78 / 5$ & 0/0/0 & $0 / 1 / 0$ & $1 / 1 / 0$ & 0/0/0 & 0/0/0 & $0 / 2 / 0$ & $1 / 4 / 0$ \\
\hline 2005 & $3 / 41 / 5$ & $4 / 11 / 0$ & $7 / 23 / 2$ & $14 / 75 / 7$ & $0 / 1 / 0$ & $0 / 1 / 0$ & $0 / 2 / 0$ & 0/0/0 & 0/0/0 & $1 / 5 / 0$ & $1 / 9 / 0$ \\
\hline
\end{tabular}

${ }^{a}$ Cryptorchidism: Q531, unilateral; Q532, bilateral; Q539, unspecified.

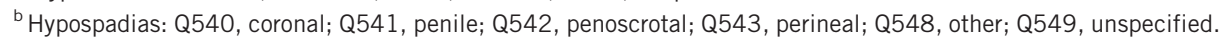


Table 3 Newly diagnosed incidence rate (per 10000 persons) of cryptorchidism and exact Poisson $95 \% \mathrm{Cl}$ between 0 and 4 years of age in 2000-2005

ncidence $(95 \% \mathrm{Cl})$

\begin{tabular}{lccc}
\cline { 2 - 4 } Year & National & Yeocheon & Ulsan \\
\hline 2000 & 5.01 & $45.66(12.44-116.9)$ & $6.09(4.01-8.85)$ \\
2001 & 11.23 & $59.24(19.24-138.3)$ & $19.02(15.08-23.68)$ \\
2002 & 11.07 & $192.6(102.6-329.3)$ & $17.95(13.99-22.68)$ \\
2003 & 15.61 & $205.7(109.5-351.8)$ & $18.55(14.38-23.56)$ \\
2004 & 16.07 & $196.1(101.3-342.5)$ & $23.20(18.34-28.95)$ \\
2005 & 17.43 & $198.0(108.3-332.2)$ & $24.37(19.17-30.55)$ \\
\hline
\end{tabular}

Abbreviation: $\mathrm{Cl}$, confidence interval.

a Yeochon and Ulsan are two industralized cities, while Chuncheon is a non-industrialized area.

survey period, the incidence of cryptorchidism in YC, compared with the national, UL and CC rates, was significantly higher. UL also showed significantly higher rates than national rates throughout the study period besides in 2000 and 2003. CC had the lowest rate compared with other regions.

\section{Hypospadias (cases per 10000 persons)}

Table 4 shows the incidence rates of hypospadias and 95\% Poisson CI at the ages of $0-4$ years, during 2000-2005. The national rate of the total newly diagnosed patients with hypospadias has significantly increased in 2001 (1.4) and 2003. The rate slightly dropped in 2004 and increased again in 2005 (3.8). YC had only four new cases throughout the whole study period (Table 1). Compared with the national rates, however, YC had higher incidences from 2003 to 2005, especially in 2004 (Table 4). The incidence in UL was slightly lower than the national level during the study period, except in 2002. There was no newly diagnosed case in CC throughout the study period besides 2003. However, the number of new cases was too small to compare yearly and regionally.

\section{DISCUSSION}

A number of animal studies have shown that in utero or perinatal exposure to industrial chemicals containing estrogenic properties or antiandrogens may cause hypospadias, cryptorchidism, reduced sperm count and testicular cancer in males, and may represent a symptom of an underlying developmental disease, the testicular dysgenesis syndrome. ${ }^{7}$ The list of chemicals that are known to affect reproduction in humans through endocrine mechanisms includes pesticides (DDT and its metabolites), polychlorinated biphenyls, dioxins, naturally occurring plant estrogens (phytoestrogens) and

Table 4 Newly diagnosed incidence rate (per 10000 persons) of hypospadias and exact Poisson $95 \% \mathrm{Cl}$ between 0 and 4 years of age in 2000-2005

\begin{tabular}{ccccc}
\hline & \multicolumn{4}{c}{ Incidence $(95 \%$ Cl) } \\
\cline { 2 - 5 } Year & National & Yeocheon & Ulsan & Chuncheon \\
\hline 2000 & 1.40 & $11.42(0.29-63.6)$ & $0.23(0.01-1.26)$ & $0(0-4.31)$ \\
2001 & 2.59 & $0(0-43.71)$ & $1.19(0.39-2.77)$ & $0(0-4.49)$ \\
2002 & 1.91 & $0(0-54.65)$ & $3.85(2.15-6.35)$ & $0(0-4.67)$ \\
2003 & 2.99 & $15.82(0.40-88.16)$ & $2.21(0.96-4.36)$ & $2.68(0.32-9.67)$ \\
2004 & 2.51 & $16.37(0.41-91.19)$ & $1.49(0.48-3.47)$ & $0(0-5.28)$ \\
2005 & 3.28 & $14.14(0.36-78.81)$ & $2.93(1.34-5.55)$ & $0(0-5.78)$ \\
\hline
\end{tabular}

Abbreviation: $\mathrm{Cl}$, confidence interval.

a Yeochon and UIsan are two industralized cities, while Chuncheon is a nonindustrialized area. mycotoxins. Several other chemicals (alkylphenols, phthalates and bisphenol A) have been shown to interfere with some endocrinemediated processes. ${ }^{10}$

However, such clear effects of an endocrine-induced disruption of chemicals on reproductive organs have not yet been shown in humans. In a systemic review of epidemiological studies with implications for the estrogen hypothesis, Storgaard et al. ${ }^{11}$ found no strong epidemiological evidence to indicate that prenatal exposure to estrogen is linked to disturbed development of the male reproductive organ, with the possible exception of testicular cancer. On the other hand, GarcíaRodríguez et al. ${ }^{12}$ observed a link between the orchidopexy rate and use of pesticides in three of four different municipalities. Kirstensen et al. ${ }^{13}$ showed an increased risk among sons of farmers and gardeners in a nationwide cohort and Weidner et al. ${ }^{14}$ reported an increased risk among sons of mothers occupied with gardening. North and Golding ${ }^{15}$ found that a vegetarian diet was associated with hypospadias, perhaps because of the phytoestrogens in this type of diet. Published studies suggest that the incidence of these congenital anomalies has increased during the past half century in developed industrial countries, but not in less developed countries, ${ }^{7}$ and evidence suggests that there is geographical variation in the prevalence of cryptorchidism and hypospadias at birth. ${ }^{16}$ Regional and temporal trends may help to identify environmental factors that might be associated with these disorders. ${ }^{7}$

Industrial development has been remarkable over the past 40 years in South Korea, which has resulted in the spread of environmental pollution. ${ }^{9}$ In the current study, the national incidence of cryptorchidism and hypospadias in males aged 0-4 years showed an increased tendency from 5.01 to 17.43 per 10000 persons and from 1.40 to 3.28 per 10000 persons, respectively, between 2000 and 2005. The incidence of cryptorchidism in YC was significantly higher than the national incidence throughout the study period, whereas the incidence in the non-polluted area (CC) was significantly lower in 2001 and 2002. UL had a significantly increased rate of hypospadias in 2002 and YC in 2004, but it was difficult to compare the rates yearly and regionally because of a small number of the congenital anomaly. There are also indications that cryptorchidism may have increased in incidence in several countries. ${ }^{17}$ The reported values are $4-42$ cases per 10000 births. In England, the incidence of cryptorchidism increased by more than $60 \%$ between the 1950 s and 1980 s. $^{10}$ The reported prevalence of hypospadias is $0.1-0.8$ per 10000 male births. ${ }^{11}$ There is also some evidence for an increase in hypospadias rates during the last few decades. ${ }^{18,19}$ On the contrary, a recent report says that the incidence of cryptorchidism in a small cohort of newborns has not changed from the $1950 \mathrm{~s}^{20} \mathrm{~A}$ review of the epidemiological data on the hypospadias amassed to date refutes claims for an increase in hypospadias rates, ${ }^{21}$ 
and there was no statistical change in hypospadias rates in the New York State from 1992 to 2005. ${ }^{22}$ It is difficult to distinguish between cryptorchidism and retractile testes, and coronal and glandular hypospadias are indistinct and may cause underreporting of cases. Differences in case ascertainment may introduce variations in reported rates of the anomalies, but the extent of confounding by these differences is unknown. Moreover, assumptions are made about the number of reference subjects, who are all not examined for the anomalies. Hospital registry data have been shown to be unreliable. ${ }^{10}$ We believe that the institutionalized standardized system (HIS, MAP and NHIRA) in Korea minimized discrepancy in the reporting system between regions and increased the reliability of the data used, although the reported number of the cryptorchidism in this study seems to be smaller than western reports. The point that we stress here is that a region of petrochemical estates had a significantly higher incidence of cryptorchidism than a non-industrialized area. Hydrocarbon compounds encountered by petrochemical workers were reported to exert a detrimental effect on human spermatogenesis, ${ }^{23}$ reduce sperm motility $^{24}$ and increase chromosomal aberrations in sperm. ${ }^{25}$ Issues that remain to be resolved are appropriate measurement of exposure to multiple petrochemical compounds that act conjointly through mechanisms similar to endogenous hormones.

However, the results in this study had some limitations to be addressed. First, we could not avoid methodological limitations of the registry-based data. The duration of residence, occupational history of parents, exposure history of endocrine disruptors in daily life, defects among stillbirths and medical history such as low birth weight and prematurity were not included. Second, the increase in incidences might also be affected by other factors such as public recognition and physician's interest. Third, the small number of the congenital anomalies, particularly for hypospadias, may not represent trends in the incidences yearly and regionally.

In conclusion, the incidences of cryptorchidism have recently increased in Korea. The higher incidences of cryptorchidism in the areas of petrochemical complexes suggest that further communitybased epidemiological studies using standardized diagnostic criteria and examination techniques are required to obtain a more precise estimation of the trends in the incidence of the anomalies and to confirm the association between petrochemicals and the anomalies.

\section{AUTHOR CONTRIBUTIONS}

All authors discussed the results and implications and commented on the manuscript at all stages. SCK developed the concept and designed the study, and wrote the paper. SKK gathered and analysed data. YPH interpreted and supervised its analysis, and edited the manuscript.

\section{COMPETING FINANCIAL INTERESTS}

The authors declare no competing financial interests.

\section{ACKNOWLEDGMENTS}

This study was supported by Ministry of Health and Welfare of Korea (A030077). We also thank Ji Eun Choi (Health Insurance Review and Assessment Service) for an informant about patient data in this study.

1 Barthold JS, González R. The epidemiology of congenital cryptorchidism, testicular ascent and orchiopexy. J Urol 2003; 170: 2396-401.

2 Foresta C, Zuccarello D, Garolla A, Ferlin A. Role of hormones, genes, and environment in human cryptorchidism. Endocr Rev 2008; 29: 560-80.

3 Borer JG, Bauer SB, Peters CA, Diamond DA, Atala A et al. Tubularized incised plate urethroplasty: expanded use in primary and repeat surgery for hypospadias. J Urol 2001; 165: 581-5.

4 Paulozzi LJ. International trends in rates of hypospadias and cryptorchidism. Environ Health Perspect 1999; 107: 297-302.

5 Khuri FJ, Hardy BE, Churchill BM. Urologic anomalies associated with hypospadias. Urol Clin North Am 1981; 8: 567-71.

6 Huyghe E, Matsuda T, Thonneau P. Increasing incidence of testicular cancer worldwide: a review. J Urol 2003; 170: 5-11.

7 Skakkebaek NE, Rajpert-De Meyts E, Main KM. Testicular dysgenesis syndrome: an increasingly common development disorder with environmental aspects. Hum Reprod 2001; 16: 972-8

8 Pohl HG, Joyce GF, Wise M, Cilento BG Jr. Cryptorchidism and hypospadias. J Urol 2007; 177: 1646-51.

9 Air Korea. Environmental Management Corporation, Ministry of Environment of Korea. Available: http://www.airkorea.or.kr/ (accessed 2 December 2009).

10 Toppari J, Kaleva M, Virtanen HE. Trends in the incidence of cryptorchidism and hypospadias, and methodological limitations of registry-based data. Hum Reprod Update 2001; 7: 282-6.

11 Storgaard L, Bonde JP, Olsen J. Male reproductive disorders in humans and prenatal indicators of estrogen exposure: a review of published epidemiological studies. Reprod Toxicol 2006; 21: 4-15.

12 García-Rodríguez J, García-Martín M, Nogueras-Ocaña M, de Dios Luna-del-Castillo J, Espigares García M et al. Exposure to pesticides and cryptorchidism: geographical evidence of a possible association. Environ Health Perspect 1996; 104: 1090-5.

13 Kristensen P, Irgens LM, Andersen A, Bye AS, Sundheim L. Birth defects among offspring of Norwegian farmers, 1967-1991. Epidemiology 1997; 8: 537-44.

14 Weidner IS, Møller H, Jensen TK, Skakkebaek NE. Cryptorchidism and hypospadias in son of gardeners and farmers. Environ Health Perspect 1998; 106: 793-6.

15 North K, Golding J. A maternal vegetarian diet in pregnancy is associated with hypospadias. The ALSPAC Study Team. Avon Longitudinal Study of Pregnancy and Childhood. BJU Int 2000; 85: 107-13.

16 Baskin LS. Hypospadias. Adv Exp Med Biol 2004; 545: 3-22.

17 Hutson JM, Hasthorpe S, Heyns CF. Anatomical and functional aspects of testicular descent and cryptorchidism. Endocr Rev 1997; 18: 259-80.

18 Paulozzi LJ, Erickson JD, Jackson RJ. Hypospadias trends in two US surveillance systems. Pediatrics 1997; 100: 831-4.

19 Aho M, Koivisto AM, Tammela TL, Auvinen A. Is the incidence of hypospadias increasing? Analysis of Finnish hospital discharge data 1970-94. Environ Health Perspect 2000; 108: 463-5.

20 Cortes D, Kjellberg EM, Breddam M, Thorup J. The true incidence of cryptorchidism in Denmark. J Urol 2008; 179: 314-8.

21 Fisch $\mathrm{H}$, Hyun G, Hensle TW. Rising hypospadias rates: disproving a myth. J Pediatr Urol 2009; 6: 37-9.

22 Fisch H, Lambert SM, Hensle TW, Hyun G. Hypospadias rates in New York State are not increasing. J Urol 2009; 181: 2291-4.

23 Lemasters GK, Olsen DM, Yiin JH, Lockey JE, Shukla R et al. Male reproductive effects of solvent and fuel exposure during aircraft maintenance. Reprod Toxicol 1999; 13: 155-66.

24 Wang SL, Wang XR, Chia SE, Shen HM, Song L et al. A study on occupational exposure to petrochemicals and smoking on seminal quality. J Androl 2001; 22: 73-8.

25 Rendon A, Rojas A, Fernandez SI, Pineda I. Increases in chromosome aberrations and in abnormal sperm morphology in rubber factory workers. Mutat Res 1994; 323: $151-7$. 